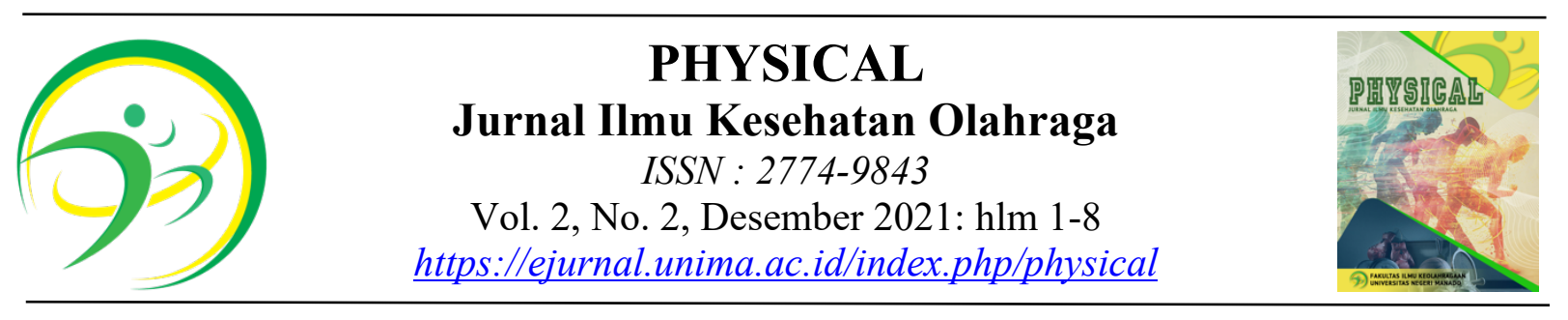

\title{
PENGARUH PENERAPAN GAYA MENGAJAR LATIHAN TERHADAP PENGUASAAN GERAK DASAR PASING BAWAH PADA PERMAINAN BOLA VOLI SISWA SMP KRISPA SILIAN
}

\author{
${ }^{1}$ Christin Mokorowu, ${ }^{2 *}$ Jes Jemmy Mangindaan, ${ }^{3}$ Agustinus Reffli Jeffri Sengkey \\ 1,2,3 Fakultas Ilmu Keolahragaan, Universitas Negeri Manado, Manado, Indonesia \\ Email Corresponding: ${ }^{2}$ jesmangindaan@unima.ac.id
}

Article Received; 17 Mei 2021; Accepted: 10 Juni 2021; Published: 30 Desember 2021

\begin{abstract}
Abstrak
Dari hasil survey di sekolah di SMP Krispa Silian pada siswa kelas VIII terlihat masih minimnya penguasaan gerak dasar dalam permainan bola voli, terutama gerak dasar pasing bawah buktinya saat melakukan proses praktek pengenalan lapangan masih banyak terjadinya kesalahan yang dilakukan oleh siswa saat melakukan gerak dasar pasing bawah, berdasarkan masalah yang di uraikan dari latar belakang tersebut, maka peneliti tertarik membuat penelitian dengan judul : "Pengaruh Penerapan Gaya Mengajar Latihan Terhadap Penguasan Ketrampilan Gerak Dasar Dalam Pasing Bawah Pada Permainan Bola Voli Siswa SMP Krispa Silian". Metode yang digunakan dalam penelitian ini adalah metode eksperimen. Berdasarkan hasil pengujian hipotesis dengan menggunakan statistik uji $t$ tersebut, maka hasil penelitian ini dapat disimpulkan bahwa terdapat pengaruh penerapan gaya mengajar latihan terhadap peningkatan penguasaan gerak dasar passing bawah dalam permainan bola voli pada siswa SMP Krispa Silian.
\end{abstract}

Kata kunci: Pasing Bawah Permainan Bola Voli, Gaya Latihan

\section{THE EFFECT OF THE APPLICATION OF EXERCISE TEACHING STYEL ON THE MASTERY OF UNDERHAND PASS IN VOLLEYBALL GAMES FOR STUDENTS AT SMP KRISPA SILIAN}

\begin{abstract}
From the results of the survey at SMP Krispa Silian in class VIII students, it is seen that there is still a lack of mastery of the basic movements in volleyball, especially the basic movements of the lower pass. Based on the problems described from this background, the researcher is interested in making a study with the title: "The Effect of the Application of Training Teaching Styles on the Mastery of Basic Movement Skills in Lower Passing in the Volleyball Game of Krispa Silian Junior High School Students". The method used in this research is the experimental method. Based on the results of hypothesis testing using the t-test statistic, the results of this study can be concluded that there is an effect of the application of training teaching styles on improving the mastery of the basic motion of underhand passing in volleyball in Krispa Silian Junior High School students.
\end{abstract}

Keywords: Underhand Pass Volleyball Game, Training Styel 


\section{Pendahuluan}

Pendidikan jasmani merupakan bagian integral dari Pendidikan secara keseluruhan yang bertujuan meningkatkan individu secara organic, neumusculer, intelektual, emosional dan sosial melalui aktivitas fisik. Pendidikan jasmani merupakan Proses pembelajaran Pendidikan jasmani memberikan manfaat kepada siswa untuk memenuhi kebutuhan gerak dasar, mengenalkan lingkungan dan potensi dirinya. Dalam proses belajar mengajar Pendidikan jasmani, terdapat banyak gaya dalam mengajar yang sering digunakan oleh guru, pemilihan gaya mengajar tergantung pada kecocokan materi yang akan diajarkan.

Pendidikan jasmani ialah salah satu mata pelajaran penting yang diajarkan di sekolah mulai dari sekolah dasar hingga sekolah menengah, "pendidikan jasmani pada dasarnya adalah pelatihan yang menggunakan kerja aktif untuk menciptakan semua perubahan yang mencakup aktifitas fisik untuk meghasilkan perubahan holistic dalam kualitas individu, baik secara fisik, mental serta emosional" Seperti halnya dalam Pendidikan umum, Pendidikan jasmani juga memiliki berbagai macam cabang olahraga yang di masukan ke dalam suatu acuan pembelajaran atau kurikulum pembelajarannya. Dimana antara lain cabang cabang olahraga tersebut ialah sepak bola, bola voli, bola basket, sepak takraw, tenis meja, senam, renang, atletic, pencak silat, bulu tangkis.

Keberhasilan dalam suatu proses pembelajaran penjas dapat dilihat dari beberapa factor yaitu guru, peserta didik, sarana prasarana, dan lingkungan yang ada di sekolah dasar. Pendidikan jasmani yang efektif perlu dipahami oleh mereka yang hendak mengajar Pendidikan jasmani, guru atau pendidik dalam proses pembelajaran Pendidikan jasmani memiliki peran penting dalam menentukan metode atau gaya mengajar, pendekatan serta menentukan media pembelajaran yang sesuai dengan materi yang diajarkan. Permainan bola voli merupakan permainan bola besar yang menjadi salah satu kurikulum pembelajaran yang diajarkan di sekolah-sekolah. Permainan bola voli mererupakan beregu yang dibagi menjadi dua tim dalam lapangan yang dipisahkan oleh net dimana setiap tim berjumlah enam orang. Dalam permainan bola voli ada beberapa teknik dasar yang harus kita kuasai baik dalam kalangan pemula maupun professional untuk mendapatkan tujuan tertentu secara efisien dan efektif, salah satunya gerak dasar pasing bawah.

Permainan bola voli di SMP Krispa Silian pada siswa kelas VIII dari hasil survey penelitian di sekolah ini terlihat masih minimnya penguasaan gerak dasar dalam permainan bola voli, terutama gerak dasar pasing bawah buktinya saat melakukan proses praktek pengenalan lapangan masih banyak terjadinya kesalahan yang dilakukan oleh siswa saat melakukan gerak dasar pasing bawah. Kurangnya kempampuan siswa saat melakukan gerak dasar pasing bawah yang disebabkan oleh factor keterbatasan sarana prasaran dan sumber bahan ajar, sehingga bakat dan minat dari siswa masih kurang sehingga cenderung tidak ada peningkatan dalam melakukan gerak dasar pasing bawah, Penggunaan metode pembelajaran kurang tepat sehingga mengakibatkan siswa kurang beradaptasi dan tidak mengembangkan kreatifitas mereka dalam mengikuti kegiatan belajar mengajar dengan kata lain siswa hanya mengikuti perintah dari guru penjas. Oleh sebab itu seorang guru harus mampu berpikir kreatif, dan mampu memahami serta memilih metode-metode pembelajaran yang dianggap tepat saat mengajarkan gerak dasar pasing bawah permainan bola voli Sehingga anak didik dapat mengebangkan semagat dan prestasi dari dalam dirinya untuk mau belajar.

Berdasarkan pengamatan di lapangan, ketrampilan gerak dasar permainan bola voli di SMP Krispa Silian masih rendah karena guru penjas belum mampu menguasai tentang penggunaan gaya mengajar Latihan yang menyebabkan proses pemberian materi kepada siswa tidak berjalan efektif dan membuat siswa sulit untuk mengerti. Oleh karena itu perlu kiranya dipilih metode pembelajran yang sesuai dengan siswa kelas VIII SMP Krispa Silian. 


\section{Metode Penelitian}

Metode yang digunakan dalam penelitian ini adalah metode eksperimen. Variable dalam penelitian ini melibatkan dua variabel. Tempat penelitin ini dilakukan di lapangan SMP Krispa Silian dan waktu penelitian dilakukan kamis dan jumat pukul 10:00 wita sampai selesai 1 bulan dengan frekuensi 2 kali seminggu.

\section{Hasil dan Pembahasan}

Adapun data hasil pengukuran kedua kelompok dalam penelitian ini adalah sebagai berikut ini :

Tabel 1. Data Hasil pengukuran gerak dasar pasing bawah Kelompok Eksperimen

\begin{tabular}{cccc}
\hline No Sampel & Pre Test & Post Test & Selisih $\left(\mathbf{X}_{\mathbf{1}}\right)$ \\
\hline 1 & 7 & 11 & 4 \\
\hline 2 & 5 & 8 & 3 \\
\hline 3 & 9 & 12 & 3 \\
\hline 4 & 6 & 9 & 3 \\
\hline 5 & 7 & 12 & 5 \\
\hline 6 & 9 & 12 & 3 \\
\hline 7 & 7 & 10 & 3 \\
\hline 8 & 8 & 12 & 4 \\
\hline 9 & 4 & 10 & 6 \\
\hline 10 & 6 & 9 & 3 \\
\hline
\end{tabular}

Tabel 2. Data Hasil pengukuran gerak dasar pasing bawah Kelompok kontrol

\begin{tabular}{cccc}
\hline No Sampel & Pre Test & Post Test & Selisih $\left(\mathbf{X}_{\mathbf{1}}\right)$ \\
\hline 1 & 8 & 10 & 2 \\
\hline 2 & 7 & 9 & 2 \\
\hline 3 & 9 & 10 & 1 \\
\hline 4 & 7 & 8 & 1 \\
\hline 5 & 6 & 7 & 1 \\
\hline 6 & 5 & 7 & 2 \\
\hline 7 & 7 & 6 & -1 \\
\hline 8 & 8 & 7 & -1 \\
\hline 9 & 6 & 6 & 1 \\
\hline 10 & 7 & 8 & 0 \\
\hline
\end{tabular}

Tabel 3. Besaran Statistik data pre tes Kedua Kelompok Kelompok Eksperimen $\left(\mathrm{X}_{1}\right) \quad$ Kelompok Kontrol $\left(\mathbf{X}_{2}\right)$

$\begin{array}{ll}\mathrm{n}=10 & \mathrm{n}=10 \\ \bar{X}_{1}=6.8 & \bar{X}_{1}=7.0 \\ \mathrm{Sdx}_{1}=1.6193 & \mathrm{Sdx}_{1}=1.1547 \\ \mathrm{~S}_{1}{ }^{2}=2.622222 & \mathrm{~S}_{1}{ }^{2}=1.333333\end{array}$


Tabel 4. Gain Score Pasing Bawah Kelompok Eksperimen dan Kelompok Kontrol

\begin{tabular}{ccc}
\hline No & Kelompok Eksperimen $\left(\mathbf{X}_{\mathbf{1}}\right)$ & Kelompok Kontrol $\left(\mathbf{X}_{\mathbf{2}}\right)$ \\
\hline 1 & 4 & 2 \\
\hline 2 & 3 & 2 \\
\hline 3 & 3 & 1 \\
\hline 4 & 3 & 1 \\
\hline 5 & 5 & 1 \\
\hline 6 & 3 & 2 \\
\hline 7 & 3 & -1 \\
\hline 8 & 4 & -1 \\
\hline 9 & 6 & 0 \\
\hline 10 & 3 & 1 \\
\hline
\end{tabular}

Untuk mendapatkan besaran-besaran statistic yang dipakai untuk analiisa data. Untuk itu jumlah skor rata-rata akan dihitung, kuadrat standar deviasi dan jumlah sampel dari data gain skor kedua kelompok dengan menggunakan program kalkulator fx-3600 pv, hasil perhitungan didaptkan :

Tabel 5. Besaran Statistik Gain Score Kedua Kelompok

\begin{tabular}{cc}
\hline Kelompok Eksperimen $\left(\mathbf{X}_{\mathbf{1}}\right)$ & Kelompok Kontrol $\left(\mathbf{X}_{\mathbf{2}}\right)$ \\
\hline $\mathrm{n}=10$ & $\mathrm{n}=10$ \\
$\bar{X}_{1}=3.7$ & $\bar{X}_{1}=0.8$ \\
$\mathrm{Sdx}_{1}=1.0593$ & $\mathrm{Sdx}_{1}=0.9189$ \\
$\mathrm{~S}_{1}{ }^{2}=1.122222$ & $\mathrm{~S}_{1}{ }^{2}=0.844444$ \\
\hline
\end{tabular}

\section{Analisis Data}

Untuk menguji apakah penerapan gaya mengajar latihan berpengaruh terhadap peningkatan gerak dasar pasing bawah dalam permainan bola voli dipakai analisis dengan teknik statistic uji beda. Agar dapat mengetahui tehnik analisa statistik yang tepat, pertama diawali dengan menguji kebutuhan analisis yang perlu dipenuhi khususnya uji normalitas dan uji homogenitas. Dalam analisis uji normalitas data menggunakan uji Lilliefors dan homogenitas varians dengan menggunakan uji varians besar berbanding varians kecil.

1. Pengujian Normalitas Data Pre Test gerak dasar passing bawah dalam permainan bola voli kelompok eksperimen.

Untuk menguji apakah sampel berasal dari populasi yang berdistribusi normal, maka dilakukan pengujian normalitas data yang menggunakan uji Lilliefors. Pengujian normalitas data dilakukan dengan langkah-langkah sebagai berikut:

a. Langkah Pertama: Menentukan Hipotesa Pengujian

$\mathrm{H}_{\mathrm{o}}$ : sampel berasal dari populasi yang berdistribusi normal

$\mathrm{H}_{\mathrm{A}}$ : sampel berasal dari populasi yang tidak berdistribusi normal

b. Langkah Kedua: Menentukan Kriteria Pengujian

Terima $\mathrm{H}_{\mathrm{O}}$ jika Lo $\leq \mathrm{Lt}$

Tolak $\mathrm{Ho}_{\mathrm{o}} \mathrm{jika}>\mathrm{Lt}$

Taraf signifikansi $\propto 0,05$

c. Langkah Ketiga: Menghitung Zi, F(Zi), S(Zi) dan Selisih Antara F(Zi)-S(Zi) serta masukan kedalam tabel.

Diketahui: $\quad \bar{X} 1=6.8$

$$
\mathrm{Sdx}_{1}=1.61
$$


Tabel 6. Perhitungan Uji Normalitas Data Pre - Test gerak dasar passing bawah dalam permainan bola voli kelompok eksperimen

\begin{tabular}{cccccc}
\hline $\mathbf{N o}$ & $\mathbf{X}_{\mathbf{1}}$ & $\mathbf{Z i}$ & $\mathbf{F}(\mathbf{Z i})$ & $\mathbf{S}(\mathbf{Z i})$ & $\mathbf{F}(\mathbf{Z i})-\mathbf{S}(\mathbf{Z i})$ \\
\hline 1 & 4 & -1.73 & 0.0418 & 0.1000 & 0.0582 \\
\hline 2 & 5 & -1.11 & 0.1335 & 0.2000 & $\mathbf{0 . 0 6 6 5}$ \\
\hline 3 & 6 & -0.49 & 0.3121 & 0.3500 & 0.0379 \\
\hline 4 & 6 & -0.49 & 0.3121 & 0.3500 & 0.0379 \\
\hline 5 & 7 & 0.12 & 0.5378 & 0.6000 & 0.0622 \\
\hline 6 & 7 & 0.12 & 0.5378 & 0.6000 & 0.0622 \\
\hline 7 & 7 & 0.12 & 0.5378 & 0.6000 & 0.0622 \\
\hline 8 & 8 & 0.74 & 0.7704 & 0.8000 & 0.0296 \\
\hline 9 & 9 & 1.36 & 0.9131 & 0.9500 & 0.0369 \\
\hline 10 & 9 & 1.36 & 0.9131 & 0.9500 & 0.0369 \\
\hline
\end{tabular}

\section{a. Langkah Keempat: Menyimpulkan Hasil Perhitungan}

Dari perhitungan di atas diperoleh selisih yang tertinggi atau L observasi nilai 0.0665 berpatokan tabel nilai kritis $L$ tabel uji Lillifors pada $\propto 0,05$ dengan $n=10$, didapatkan nlai 0.258 untuk L tabel. Berpatokan pada kriteria pengujian jika Lo $<$ Lt maka Ho diterima. Untuk itu dapat disimpulkan pengujian sampel berasal dari populas yang berdistrbusi normal.

\section{Pengujian Normalitas Data Pre Test gerak dasar passing bawah dalam permainan bola voli kelompok kontrol}

Untuk menguji apakah sampel berasal dari populasi yang berdistribusi normal maka dilakukan pengujian normalitas data dengan menggunakan uji lillifors. Pengujian normalitas data dilakukan dengan langkah-langkah sebagai berikut:

a. Langkah Pertama: Menentukan Hipotesa Pengujian

$\mathrm{H}_{\mathrm{o}}$ : sampel berasal dari populasi yang berdistribusi normal

$\mathrm{H}_{\mathrm{A}}$ : sampel berasal dari populasi yang tidak berdistribusi normal

b. Langkah Kedua: Menentukan Kriteria Pengujian

Terima $\mathrm{H}_{\mathrm{O}}$ jika Lo $\leq \mathrm{Lt}$

Tolak $\mathrm{H}_{\mathrm{O}}$ jika $>\mathrm{Lt}$

Taraf signifikansi $\propto 0,05$

c. Langkah Ketiga: Menghitung Zi, F(Zi), S(Zi) dan Selisih Antara F(Zi)-S(Zi) serta masukan kedalam tabel.

Diketahui: $\bar{X} 2=7.0$

$$
\mathrm{Sdx}_{2}=1.15
$$

Tabel. 6. Perhitungan Uji Normalitas Data Pre - Test gerak dasar passing bawah

\begin{tabular}{cccccc}
\multicolumn{6}{c}{ dalam permainan bola voli kelompok kontrol } \\
\hline No & $\mathbf{X}_{\mathbf{1}}$ & $\mathbf{Z i}$ & $\mathbf{F}(\mathbf{Z i})$ & $\mathbf{S}(\mathbf{Z i})$ & $\mathbf{F}(\mathbf{Z i})-\mathbf{S}(\mathbf{Z i})$ \\
\hline 1 & 5 & -1.73 & 0.0418 & 0.1000 & $\mathbf{0 . 0 5 8 2}$ \\
\hline 2 & 6 & -0.86 & 0.1949 & 0.2500 & 0.0551 \\
\hline 3 & 6 & -0.86 & 0.1949 & 0.2500 & 0.0551 \\
\hline 4 & 7 & 0.00 & 0.5000 & 0.5500 & 0.0500 \\
\hline 5 & 7 & 0.00 & 0.5000 & 0.5500 & 0.0500 \\
\hline 6 & 7 & 0.00 & 0.5000 & 0.5500 & 0.0500 \\
\hline 7 & 7 & 0.00 & 0.5000 & 0.5500 & 0.0500 \\
\hline 8 & 8 & 0.86 & 0.8051 & 0.8500 & 0.0449 \\
\hline 9 & 8 & 0.86 & 0.8051 & 0.8500 & 0.0449 \\
\hline 10 & 9 & 1.73 & 0.9582 & 1.0000 & 0.0418 \\
\hline
\end{tabular}




\section{d. Langkah Keempat : Menyimpulkan Hasil Perhitungan}

Dari perhitungan di atas diperoleh selisih yang tertinggi atau $\mathrm{L}$ observasi nilai= 0.00582. berpatokan nilai kritis $L$ tabel uji Lillifors dalam $\propto 0,05$ dengan $n=10$, ditemukan L tabel senilai 0.258. Berdasarkan patokan pengujian jika Lo $<$ Lt maka Ho diterima. Untuk itu kesimpulan pengujian ialah sampel bersumber pada populasi yang berdistribusi normal.

\section{B. Pengujian Homogenitas Varians}

Tujuan dari pengujian homogenitas dalam penelitian ini adalah untuk mengetahui apakah varians dari populasi penelitian homogen atau tidak. untuk mengetahui apakah varians populasi homogen maka dilakukan pengujian homogenitas dengan rumus varians terbesar dibanding varians terkecil.

Tabel 7 Uji homogenitas varians dengan varians terbesar berbanding varians terkecil

\begin{tabular}{ccc}
\hline $\begin{array}{c}\text { Nilai Varians } \\
\text { Sampel }\end{array}$ & \multicolumn{3}{c}{ Jenis Variabel } \\
\hline & $\mathbf{S}^{\mathbf{2}}$ & $\mathbf{S}^{\mathbf{2}} \mathbf{}_{\mathbf{2}}$ \\
\hline $\mathrm{S}$ & 2.622222 & 1.333333 \\
$\mathrm{~N}$ & 10 & 10 \\
\hline
\end{tabular}

Langkah-langkah pengujian homogenitas varians dengan menggunakan uji homogenitas varians terbesar dibanding varians terkecil adalah sebagai berikut:

a. Langkah pertama: membagi nilai varians terbesar dan varians terkecil dengan rumus:

$\mathrm{F}==\frac{2.62222}{1.333333}=1.966666=1.97$ (dibulatkan)

b. Langkah kedua: membandingkan nilai $\mathbf{F}$ hitung dengan $\mathbf{F}$ tabel dengan rumus:

$\mathrm{dk}$ pembilang $=\mathrm{n}-1=10-1=9$ (untuk varians terbesar)

$\mathrm{dk}$ penyebut $=\mathrm{n}-1=10-1=9$ (untuk varians terkecil)

taraf signifikansi $\alpha 0,05$, maka dicari pada tabel $\mathrm{F}$ sehingga didapat $\mathrm{F}$ tabel $=3.18$

Dengan kriteria pengujian sebagai berikut:

Jika $F$ hitung $\geq F_{\text {tabel }}$ berarti tidak homogen dan jika $F$ hitung $\leq F_{\text {tabel }}$ berarti homogen.

Ternyata $\mathrm{F}$ hitung $<\mathrm{F}_{\text {tabel }}$ atau $1.97<3.18$, maka varians dalam populasi adalah homogen.

Berdasarkan pengujian persyaratan analisis yakni pengujian normalitas data dan pengujian homogenitas varians, ternyata memenuhi syarat yakni popuasi normal dan homogen, dengan demikian pengujian hipotesa penelitian dapat dilanjutkan dengan uji parametrik.

\section{Pengujian Hipotesa Penelitian}

Hipotesa yang akan diuji dalam penelitian ini adalah pengaruh gaya mengajar latihan terhadap peningkatan gerak dasar passing bawah dalam permainan bola voli pada siswa SMP Krispa Silian. Untuk menguji hipotesa tersebut berarti membandingkan rata-rata peningkatan gerak dasar passing bawah dalam permainan bola voli kelompok eksperimen yang mendapat perlakuan dengan gaya mengajar latihan yang diberikan selama satu bulan dengan peningkatan 
gerak dasar passing bawah dalam permainan bola voli kelompok kontrol yang tidak mendapatkan perlakuan, maka rumus yang sesuai untuk itu adalah uji -t sebagai berikut:

$\mathrm{t}_{\text {hitung }}=\frac{\overline{\mathrm{x}}_{1}-\overline{\mathrm{x}}_{2}}{\sqrt[\mathrm{s}]{\frac{1}{\mathrm{n}_{1}+\frac{1}{\mathrm{n}_{2}}}}}$

Dimana: $\mathrm{S}^{2}=\frac{\left(n_{1}-1\right) S_{1}^{2}+\left(n_{2}-1\right) S_{2}^{2}}{n_{1}+n_{2}}$

Langkah-langkah pengujian hipotesa penelitian adalah sebagai berikut:

a. Langkah Pertama: Menentukan Hipotesa Pengujian

Ho: Rata-rata peningkatan penguasaan gerak dasar passing bawah dalam permainan bola voli kelompok eksperimen yang diajar dengan gaya mengajar latihan sama dengan atau lebih kecil dari rata-rata peningkatan penguasaan gerak dasar passing bawah dalam permainan bola voli kelompok kontrol yang tidak mendapatkan perlakuan.

$\mathrm{H}_{\mathrm{A}}$ : Rata-rata peningkatan penguasaan gerak dasar passing bawah dalam permainan bola voli kelompok eksperimen yang diajar dengan gaya mengajar latihan lebih besar dari rata-rata peningkatan penguasaan gerak dasar passing bawah dalam permainan bola voli kelompok kontrol yang tidak mendapatkan perlakuan.

\section{Hipotesa statistiknya adalah:}

$$
\begin{aligned}
& \mathrm{Ho}=\mu_{1} \leq \mu_{2} \\
& \mathrm{H}_{\mathrm{A}}=\mu_{1}>\mu_{2}
\end{aligned}
$$

b. Langkah Kedua: Menentukan Kriteria Pengujian

Terima Ho jika $\mathrm{t}_{\text {hitung }} \leq \mathrm{t}$ tabel $\left(\propto 0,05 ; d k=n_{1}+n_{2}-2\right)$ artinya tidak signifikan

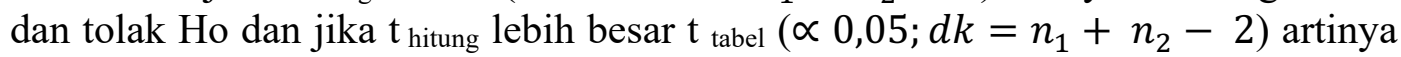
signifikan.

c. Langkah Ketiga: Memasukkan besaran statistik kedalam rumus

Sebelum dimasukkan kedalam rumus uji t, maka terlebih dahulu dihitung standar deviasi gabungan $(\mathrm{S})$.

$$
\begin{aligned}
& \mathrm{S}^{2}=\frac{\left(n_{1}-1\right) S_{1}^{2}+\left(n_{2}-1\right) S_{2}^{2}}{n_{1}+n_{2}-2} \\
= & \frac{(10-1) 1.122222+(10-1) 0.844444}{10+10-2} \\
= & \frac{(9) 1.122222+(9) 0.844444}{18} \\
= & \frac{10.099998+7.599996}{18} \\
= & \frac{17.699994}{18} \\
\mathrm{~S}^{2}= & 0.983333 \\
\mathrm{~S} & =\sqrt{0.983333} \\
= & 0.99
\end{aligned}
$$

$$
\begin{aligned}
& \text { thitung }=\frac{\bar{X}_{1}-\bar{X}_{2}}{S \sqrt{\frac{1}{n_{1}}+\frac{1}{n_{2}}}} \\
& =\frac{3,7-0.8}{0.99 \sqrt{\frac{1}{10}+\frac{1}{10}}} \\
& =\frac{2.9}{0.99 \sqrt{0,1+0,1}} \\
& =\frac{2.9}{0.99 \sqrt{0.2}} \\
& =\frac{2.9}{0.99(0,4447213)}
\end{aligned}
$$




$$
\begin{aligned}
& =\frac{2.9}{0.442741} \\
& =6.5501 \\
& =6.55
\end{aligned}
$$

Berdasarkan hasil pengujian hipotesis dengan menggunakan statistik uji t tersebut, maka hasil penelitian ini dapat disimpulkan bahwa terdapat pengaruh penerapan gaya mengajat latihan terhadap peningkatan penguasaan gerak dasar passing bawah dalam permainan bola voli pada siswa SMP Krispa Silian.

\section{Kesimpulan}

Berdasarkan hasil penelitian dan pembahasan yang telah di kemukakan sebelumnya, maka dapatlah ditarik beberapa kesimpulan yaitu sebagai berikut:

Hasil pengujian hipotesa penelitian didapatkan nilai thitung 6.55. Berpatokan pada tabel distribusi t pada $\propto 0,05$ dengan derajat kebebasan $\mathrm{n}_{1}+\mathrm{n}_{2}-2=10+10-2=18$ maka didapatkan nilai $t_{\text {tabel }}$ senilai 2.101. Jadi $t_{\text {hitung }}$ lebih besar dari $t_{\text {tabel }}$, yaitu $t_{\text {hitung }}=6.55>t_{\text {tabel }}=2.101$.

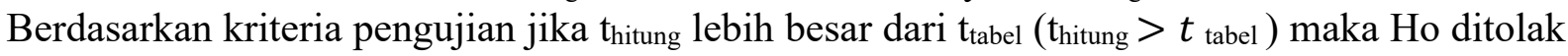
yang berarti $\mathrm{H}_{\mathrm{A}}$ diterima. Untuk itu kesimpulan dalam penelitian ini adalah, Terdapat pengaruh penerapan gaya mengajar latihan terhadap penguasaan gerak dasar passing bawah

\section{Daftar Pustaka}

Anonim. 2017, Http://sipuu.setkab.go.id/PUUdoc/7308/UU0202003.html. Diakses pada tanggal 12 Maret 2017

Ary Donald, dkk, 2015, Pengantar Penelitian Dalam Pendidikan, Terjemahan Arief Furchan. Usaha Nasional, Cetakan Ke VII.

Bahri Syaiful Djamarah dan Aswan Zain, 2010, Strategi Belajar Mengajar. Rineka Cipta Jakarta, Hal. 96.

Danim Sudarwan, 2013, Pengantar Kependidikan Landasan, Teori, dan 234 Metafora Pendidikan. Alfabeta, Bandung, Hal. 2.

Drs. Machud Irsyaada, 2015, Gerak dasar permainan bola voli, hal 17

https://www.google.com/search?q=gambar+passing+bawah\&0q=gambar+passing+b awah\%

http://www.google.com/search?q=lapangana+tes+passing+bawah.com diakses 29september 2019

Mahendra dan Agus, 2000, Modul Senam.Depdiknas Dikjen Pendidikan Dasar dan Menengah Bagian Proyek Penataran Guru SLTP Setara D-III, Hal. 44.

Ma'mun A. dan Yuda S., 2001, Perkembangan Gerak Dan Belajar Gerak. Halaman 20-21

Rahantoknam E., 2011, Strategi Instruksional dalam Pendidikan Olahraga.FPSIKIP, Jakarta 1998, Hal. 1Surabaya 2011, Hal. 287.

Sudijono A., 1999, Pengantar Statistik Pendidikan. PT Raja Grafindo Persada, Jakarta, Hal. 26.

Suharsimi Arikunto, 2008, Metodologi penelitian. Bina aksara, Yogyakarta 2008, Hal. 116.

Syafudin dan Sudrajat W, 2014, Pendidikan Jasmani, Olahrag, dan Kesehatan, Jakarta, hal.1819

Wiryaman S.A., 1992, Strategi dan Metode Belajar Mengajar. Direktorat Jenderal Pendidkan Tinggi Universitas Terbuka, Jakarta 